\title{
Are We There Yet? Addressing Diversity in Political Science Subfields
}

\author{
Rebecca A. Reid, University of Texas at El Paso \\ Todd A. Curry, University of Texas at El Paso
}

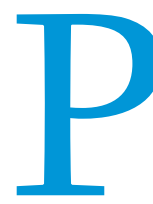

olitical science departments, along with the colleges and universities within which they operate, seek to diversify for various reasons. However, despite these efforts-often representing millions of dollars' worth of investment (Sinclair-Chapman 2015)-political science remains a predominantly white male field. We are not the first to note the lack of diversification. PS: Political Science $\mathcal{E}$ Politics has published several articles and symposia on issues of diversity. However, the majority of publications pertaining to these issues assume a predominantly gender-focused perspective. From 1993 to 2017, more than 50 articles pertained to gender inequalities in the profession, whereas only a few articles addressed racial and ethnic disparities or other forms of diversity, including one symposium on LGBTQ issues in the January 2011 issue. ${ }^{1}$ Although many of these gender-oriented articles include acknowledgment of other dimensions of diversity and intersectionality, the lack of those focusing on these dimensions is noticeable. Indeed, the majority can address changes in the participation of only white women in the field; people of color are relegated as the catch-all for all non-white individuals because there simply are too few non-white scholars to systematically evaluate. Furthermore, this lack of representation means that we, as a field, cannot address how women of color and other intersectional groups experience compounded inequalities and disenfranchisement.

Our ability to address these deficiencies hinges on our efforts to evaluate the current state of the discipline-in terms of membership in the field as well as the processes that hinder meaningful inclusion. Hence, we surveyed our Public Law Section to better evaluate our progress in its diversification efforts. We emailed a survey to all 480 Law and Courts Section members ${ }^{2}$ to establish our basic demographics. We received 295 responses, a $61 \%$ response rate, to a series of five questions. The questions inquired about an individual's gender, age, ethnicity, employment situation, and academic affiliation. We present the raw results of the survey and reflect on how our section compares to other APSA sections and academia more generally.

Although APSA provides data on discipline and subfield demographics through its new dashboard, 3 these data are in the aggregate and proprietary. Our survey measure enabled us to evaluate individual-level data and examine more than only descriptive statistics. It is useful to know, for example, the proportion of women of color in public law. The APSA dashboard can

Rebecca A. Reid is assistant professor in political science at the University of Texas at El Paso. She can be reached at rareid@utep.edu and tweets @Rebecca_A_Reid.

Todd A. Curry is assistant professor in political science at the University of Texas atE1 Paso. He can be reached at tacurry@utep.edu and tweets @DrToddACurry.This article originally appeared in the Spring 2017 Law and Courts Newsletter. display women or people of color in the field; however, it cannot do both. This limits its usefulness to subfields that want to take targeted action to improve intersectional diversity within their membership.

Unfortunately, we cannot present individual-level data on several groups of people of color or on sexual orientation because such a discussion would inadvertently identify individual members of our section. There is so little representation across the dimensions of sexual orientation and intersectionality that to discuss them would be to "out" individual scholars. ${ }^{4}$ Thus, to protect their anonymity and privacy, we omitted these important dimensions. Nonetheless, the very lack of representation should indicate the utter lack of progress in these dimensions. This is a massive problem.

Despite the conscientious efforts of members in our section, we found that women reflect only $35 \%$ of the Law and Courts membership (figure 1). Although this is higher than the $29 \%$ of women in APSA in 2010, it remains lower than the $49 \%$ of female faculty within academia generally as of 2013 (Toven 2015). Hence, a 14\% gap exists between the proportions of female faculty in public law and those in academia more generally. APSA lags behind the rest of academia by nearly 20 percentage points.

The average APSA subfield has approximately 38\% female membership; however, there exists significant dispersion around that number (figure 2). Notable outliers include political methodology, with $19.92 \%$ female membership, and women and politics, with $91.67 \%$. In fact, 37 subfields within political science fall below the 2013 average number of women in academia. Thus, gender disparity remains a systemic problem: 37 of 44 total (reported) subfields still fail to reach parity.

Similar issues appear regarding ethnic diversity-although the contrast is even starker. Within the Law and Courts Section, nearly $90 \%$ of our membership identifies as non-Hispanic white. This is a full $15 \%$ gap between our subfield and academia more generally, in which $77 \%$ of full-time faculty identified as white in 2015 (US Department of Education 2017). As shown in figure 3, Hispanics and African Americans comprised barely 5\% of the membership in the Law and Courts Section in 2016. Asian Americans represent roughly $4 \%$ of our membership. This survey also revealed that only one member identifies as American Indian/Alaskan Native, and only one member identifies as Pacific Islander. These numbers lag behind APSA 2011 memberships, in which Hispanics and African Americans comprised nearly $10 \%$ of all APSA membership (Fraga, Givens, and Pinderhughes 2011). 5 Yet, this ethnic diversity represented in our discipline in 2011 was not evenly distributed across subfields (figure 4). Only seven subfields (i.e., democratization; comparative politics; political economy; African politics; urban and local politics; migration and citizenship; and race, ethnicity, and politics) were more inclusive 
than the 2015 national average of full-time faculty (US Department of Education 2017). Thus, despite its efforts, the Law and Courts Section-as well as APSA more generally-suffers from severe systemic underrepresentation of people of color.

Addressing the intersection of ethnicity and gender, our survey revealed that $90 \%$ of men in the Law and Courts Section are non-Hispanic white-which markedly surpasses the 2015 national average in which $78 \%$ of full-time faculty identify as white males (US Department of Education 2017). Only 1\% of public law males are African American, which similarly fails to reach the meager 2015 national average of $3 \%$. Only $4 \%$ of male public law scholars identify as Asian or Asian American, and the Pacific Islander and American Indian/Alaskan categories are too small to be reported. These numbers similarly fail to reach the 2015 national average in which $6 \%$ of faculty represented Asian/Asian Americans and Pacific Islanders. Less than $4 \%$ of
Department of Education 2017). In fact, women in public law mainly represent only three ethnic categories: white (89.22\%), Asian or Asian American (3.92\%), and African American (6.86\%). Only one person (who did not participate in the survey) is a Hispanic female, and no women represent American Indian/Alaskan or Pacific Islander ethnicities. The public law representation of Asian and Asian American identities is similar to the 2015 national average, in which $4 \%$ of full-time faculty women were represented. However, this national average included Pacific Islanders, which is not currently represented in the Public Law Section. The section falls short of the national average of $2 \%$ Hispanic women. African American women in the Law and Courts Section actually surpassed the 2015 national average of 3\% (US Department of Education 2017). However, single-digit representation of women of color is unacceptable.

\section{Despite the conscientious efforts of members in our section, we found that women reflect only $35 \%$ of the Law and Courts membership (figure 1). Although this is higher than the $29 \%$ of women in APSA in 2010, it remains lower than the $49 \%$ of female faculty within academia generally as of 2013 (Toven 2015).}

Law and Courts Section males identify as Hispanic, which is actually more than the 2015 national average of $2 \%$. Nationally, $1 \%$ or less of faculty represent American Indian/Alaskan Native identities (US Department of Education 2017). Hence, these groups remain underrepresented in academia as well as in political science and public law.

Only $11 \%$ of Law and Courts membership are women of color. Of the public law women, $89 \%$ identify as non-Hispanic white-which surpasses the national average for academia in which $77 \%$ of full-time faculty identify as white women (US

\section{Figure 1 \\ Gender Diversity in Law and Courts}

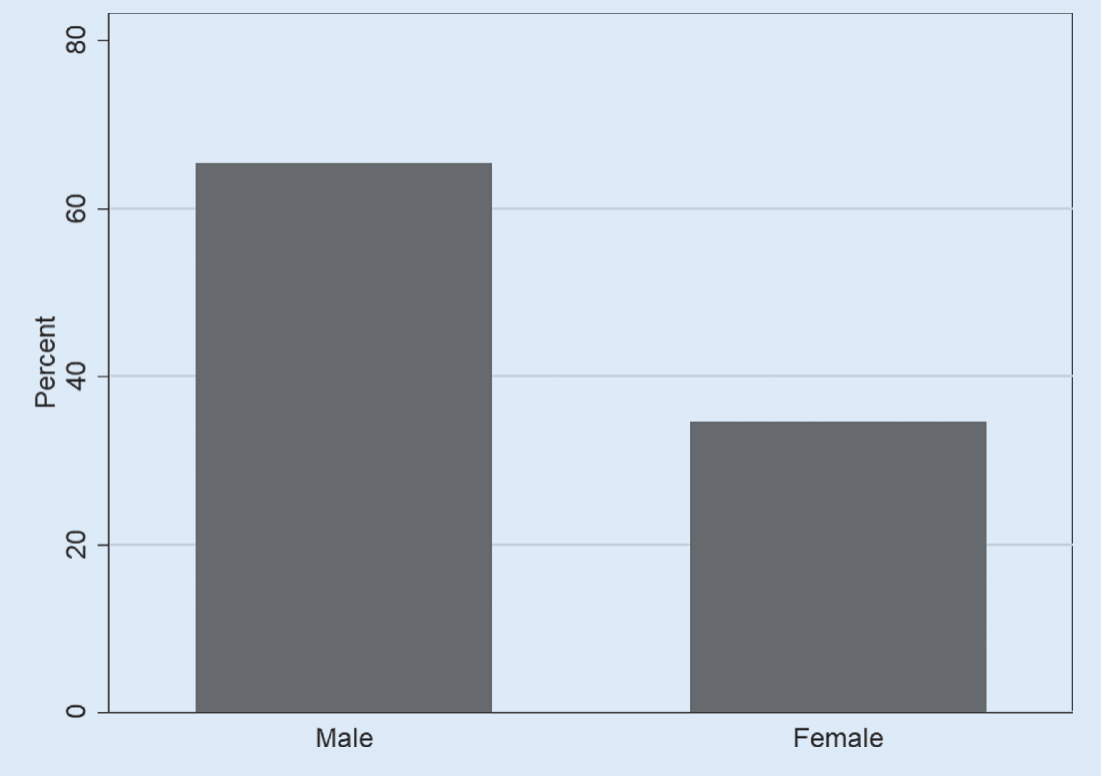

\section{WHAT ARE WE DOING WRONG AND HOW DO WE FIX IT?}

One explanation for the lack of diversity is that too few minorities earn doctorate degrees and enter the job market. This "pipeline" problem was discredited by Monroe et al. (2014) and by APSA Placement surveys that instead show that people of color are not getting hired. In 2015-2016, surveys show that $19.2 \%$ of black job candidates, $13.7 \%$ of Asian or Pacific Islanders, and $28.6 \%$ of "other" ethnicities were not placed at all. Hence, there are enough minority job candidates to fill (tenure-track) faculty positions. Our faculty should be at least as representative as the pool from which departments are hiring. We have minority scholars seeking jobs; we just need to hire them. ${ }^{6}$

Furthermore, we must work to retain faculty of color by fixing the "leaky pipeline" (APSA Task Force 2004; Evans and Moulder 2011; Monforti and Michelson 2008). A disproportionate number of women and people of color leave the discipline due to various problems, including gendered and racial disparities in likelihood of promotion (Mershon and Walsh 2015), salary disparities (Ginther 2004; Henehan and Sarkees 2009), job and professional satisfaction (Hesli and Lee 2013), experiences with discrimination (Hesli 2013; Novkov and Barclay 2010), and hostile climates in research and teaching (AlexanderFloyd 2008; Mathews and Andersen 2001). In short, our field tacitly perpetuates the same underlying systemic inequalities and biases that plague our society. Furthermore, at no point can our scholars break free from these hurdles. They remain at all levels of 
academia because they are fostered by virtually all of the processes associated with political science's evaluation of merit and advancement.

Even from the outset, lack of representation implicitly tells our minority students that they are not welcome when they do not see faculty who look like them, which limits recruitment. Similarly, academia remains exclusionary through its use of "colorblind" hiring processes, which simply ignore systemic inequalities and contribute to racism (Greenberg 2015). Even after a scholar is in the discipline, the lack of diversity perpetuates white male power in terms of the types of research our field produces and prioritizes. Accepted paradigms determine which research agendas are appropriate and valuable, and these paradigms systematically
These scholars are similarly penalized in teaching. Despite the benefits to students because faculty of color and women are more likely to use active-learning techniques and student-centered approaches than their male colleagues (Milem 1997) and more likely to include perspectives of minorities in their curriculum (Milem 2003), they are systematically biased against in student evaluations (Lilienfeld 2016; Uttl, White, and Gonzalez 2017). Indeed, teaching excellence appears to be acknowledged only by their peers in that women receive more teaching awards than their male colleagues-but only in research-oriented institutions that prioritize research for tenure (Butcher and Kersey 2015). Hence, teaching excellence-when credited-directly undermines their professional advancement.

\section{One explanation for the lack of diversity is that too few minorities earn doctorate degrees and enter the job market. This "pipeline" problem was discredited by Monroe et al. (2014) and by APSA Placement surveys that instead show that people of color are not getting hired.}

devalue research pertaining to race, ethnicity, gender, sexuality, and identity, as well as qualitative work. Scholars who engage in this work often are penalized because it is not perceived as "scientific" (Brettschneider 2011; Hesli and Lee 2013; Thomas 2017). This devaluation is similarly reflected in their absence in prestigious journals (Breuning and Sanders 2007; Evans and Moulder 2011; Teele and Thelen 2017) and the lack of citations to these scholars' work (Maliniak, Powers, and Walter 2013). Because these types of research often are pursued by scholars of color and women, these groups are disproportionately marginalized. Women of color are doubly penalized where they are relegated to "space invaders" because they remain outside both the gendered and racial norms of the discipline (Alexander-Floyd 2015).

\section{Figure 2}

\section{APSA Subfields by Female Membership}

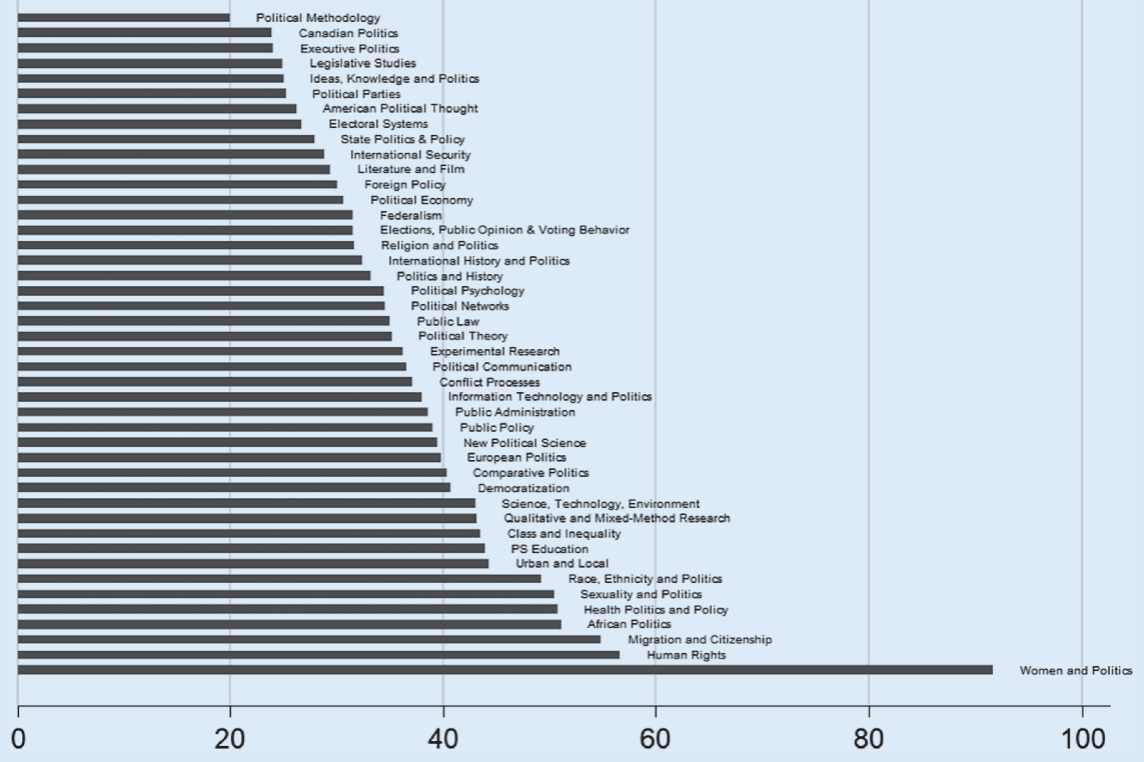

In terms of service, scholars of color and women end up serving as "tokens," overwhelmingly relied on for service on committees (Mitchell and Hesli 2013; Pyke 2011). Service and teaching further intersect when scholars of color and women take on the more invisible labor of student mentorship and advising (June 2015; Whitaker 2017). Hence, especially for women of color, these scholars are invisible or marginalized as competent researchers, underappreciated in teaching (or appreciated at their own professional detriment), and hyper-visible in service in which institutions extract additional labor from them (Alexander-Floyd 2015; Padilla 1994). Scholars of color and women are penalized literally at every step of their academic career.

Despite the plethora of empirical support revealing these systemic failures, political science and public law simply have not done enough to address them. Whereas some changes could be instituted immediately, most solutions likely will require longer-term strategies. Indeed, these systemic biases must be addressed head on, and training workshops discussing equal opportunity do not cut it.

Perhaps the main reason for our discipline's failure to adequately redress these issues is its assumption that diversification requires a tradeoff with scientific excellence, rigor, and academic prestige (Alvarez 2017; Hero 2015). Scientific excellence and merit are not mutually exclusive from diversification and inclusion. Indeed, excellence does not have a single legitimate definition. Political science prides itself for being "objective" and "scientific," which are largely equated with quantitative research on "appropriate" or "legitimate" research 
agendas dictated by the inheritance of the Western, white, heteronormative, male template for education and science (Thomas 2017). To the extent that our field thereby marginalizes and excludes research agendas, epistemologies, and methods that do not neatly fit into this framework, we are perpetuating and reproducing the same discriminatory barriers-which are entirely contradictory to the mission of education. Substantively, scholars who focus on critical theory, race, gender, ethnicity, sexuality, and each subfield to take an accurate accounting of its membership. This foundational step will allow section leadership to develop a personalized strategy that targets the goals for each subfield. Furthermore, we must account for our failures to acknowledge women of color and others who have been systematically marginalized and ignored, even by APSA membership data. At a minimum, data collection must include intersectional identities. We cannot revise our policies without these data. In summary,

\section{To the extent that our field thereby marginalizes and excludes research agendas, epistemologies, and methods that do not neatly fit into this framework, we are perpetuating and reproducing the same discriminatory barriers-which are entirely contradictory to the mission of education.}

identities (among others) are marginalized because these research agendas are criticized as not being science, as only attractive to specialized audiences, as self-serving, as voluntary marginalization through identity politics, as confusing one's professional and personal lives, and as political advocacy and lobbying masquerading as scholarship (Mucciaroni 2011). Yet, these scholars undergo the same courses, research training, and peer-review processes. Hence, their exclusion is derived mostly from the superiority complex inherited by discriminatory traditions perpetuated by mainstream scholars who seem to derive their self-worth from being in an elite class defined by its exclusionary nature.

Therefore, we can and should have an inclusive, diverse field of scholars who produce rigorous, innovative scientific research. There is no tradeoff. Once we decide to relinquish the myth of superiority that excludes these scholars, we finally can begin the effortful discussion and reform to generate an inclusive community of scholars. The onus falls on each of us. We challenge

\section{Figure 3}

Ethnic Diversity in Law and Courts

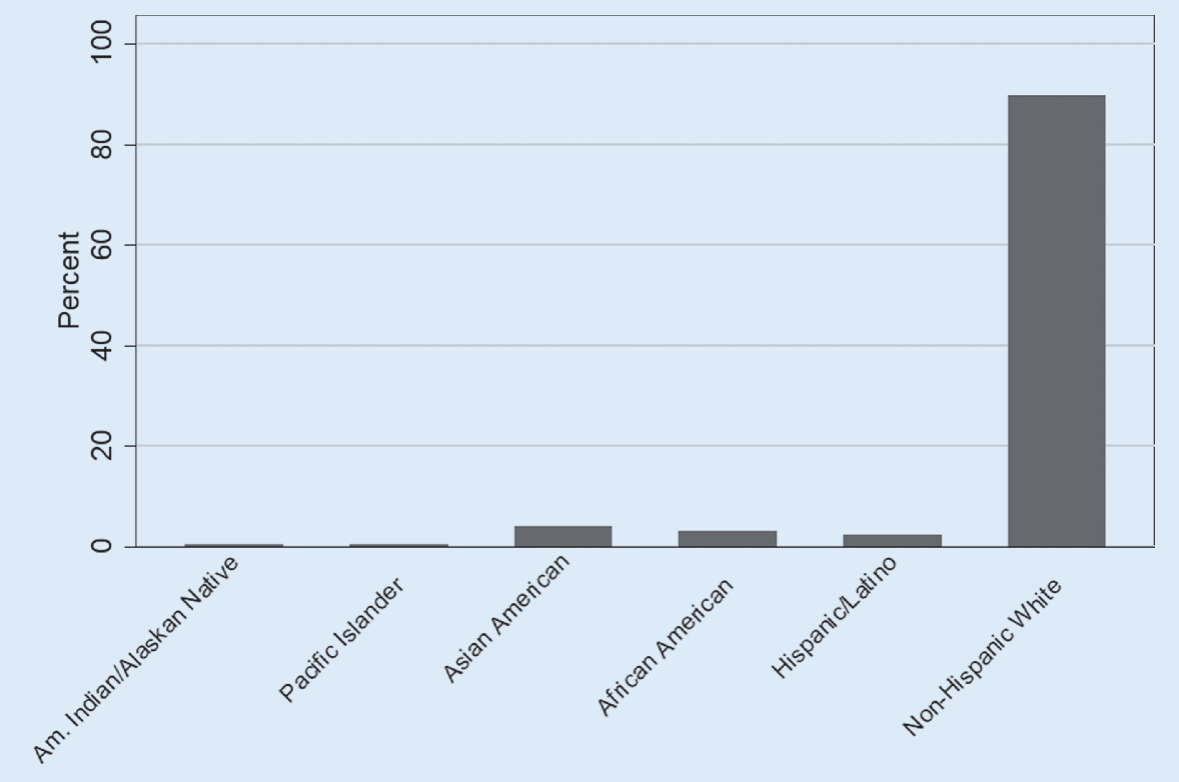

without this acknowledgment, evaluation, discussion, and deliberate reform, the damning response to why there is no diversity in academia will truly be because we do not want it.

\section{NOTES}

1. However, this symposium predominantly addressed the contribution of the study of LGBTQ politics to political science rather than directly addressing the extent of diversity across these identities within the discipline itself.

2. This population includes all dues-paying members of APSA's Law and Courts Section on April 2, 2016.

3. Available at www.apsanet.org/Resources/Data-on-the-Profession.

4. Although the complete value of a subfield-specific survey device cannot be fully displayed in this format, the value of being able to analyze diversity and intersectionality by age and employment, for example, would be of high value to subfields looking to take meaningful action.

5. The data that were shared were aggregate statistics already categorized by subfield; therefore, we do not have more up-to-date measures for APSA as a whole.

6. A related argument suggests that minorities who do earn degrees are in such high demand that they have their choice of jobs and receive multiple offers, essentially creating a bidding war in which non-elite institutions lose out (Smith 2000). However, the fact that many minority job candidates are not getting hired at all refutes this argument. Similarly, some assert that minorities seek only prestigious jobs (presumably because of their high demand)-which again seems unlikely because many are not being hired at all and many are not receiving tenure-track jobs. More specifically, $15.4 \%$ of black job candidates, $12.6 \%$ of Asian or Pacific Islander candidates, $20 \%$ of "other" ethnicities candidates, $20 \%$ of candidates of two or more races, and $18.8 \%$ of unknown race/ethnicity candidates secured non-tenure track positions in 2015-2016.

\section{REFERENCES}

Alexander-Floyd, Nikol. 2008. “'Written,

Published...Cross-Indexed, and Foot-Noted':

Producing Black Female PhDs and Black

Women's and Gender Studies Scholarship in

Political Science." PS: Political Science \& Politics 41 (4): 819-29.

Alexander-Floyd, Nikol. 2015. "Women of Color, Space Invaders, and Political Science: Practical Strategies for Transforming Institutional Practices." PS: Political Science \& Politics 48 (3): 464-68.

Alvarez, Maximillian. 2017. “Academe’s Prestige Problem." The Chronicle of Higher Education. Available at www.chronicle.com/article/ Academe-s-Prestige-Problem/241432. 


\section{Figure 4 \\ APSA Subfields by Non-White Membership}

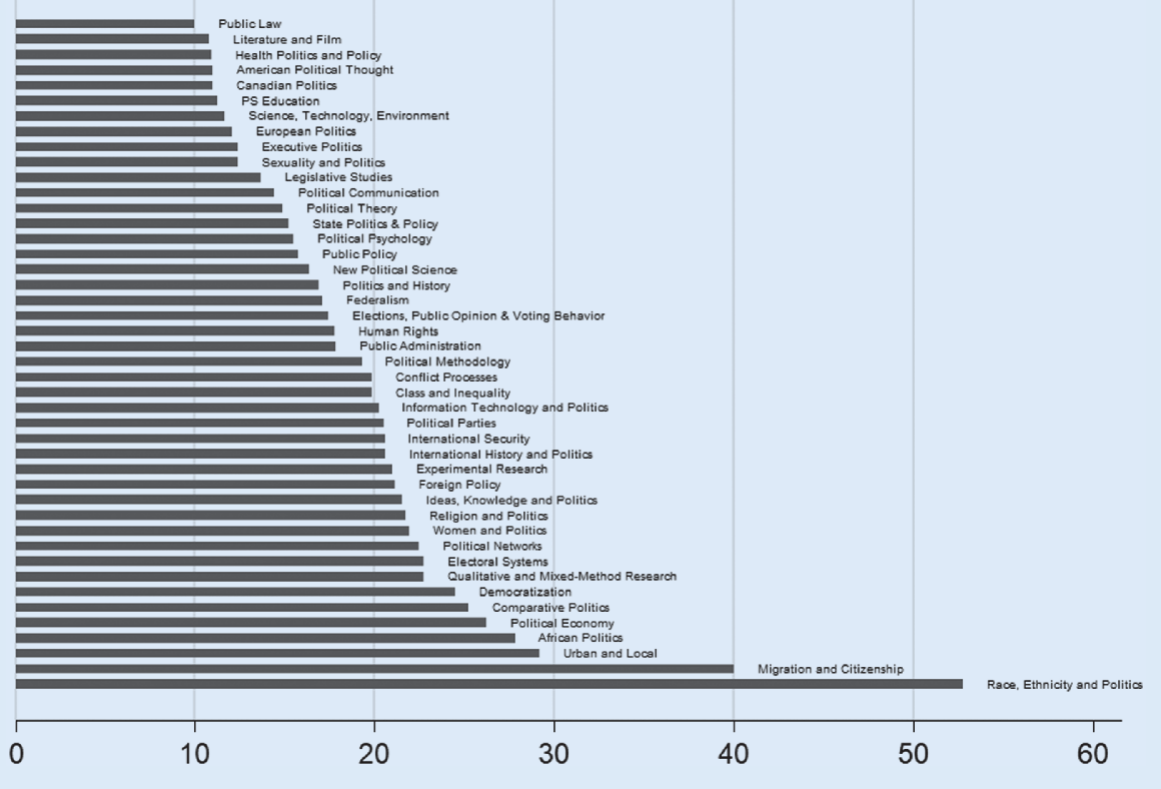

Maliniak, Daniel, Ryan Powers, and Barbara F. Walter. 2013. "The Gender Citation Gap in International Relations." International Organization 67 (4): 1-34.

Mathews, A. Lanethea, and Kristi Andersen. 2001. "A Gender Gap in Publishing? Women's Representation in Edited Political Science Books." PS: Political Science \& Politics 31 (1): 143-47.

Mershon, Carol, and Denise Walsh. 2015. "How Political Science Can Be More Diverse.” PS: Political Science \& Politics 48 (3): 441-44

Milem, Jeffrey F. 1997. Key Educational Outcomes of Diversity for College and University Faculty. Cambridge, MA: Harvard Educational Publishing Group.

Milem, Jeffrey F. 2003. "The Educational Benefits of Diversity: Evidence from Multiple Sectors." In Compelling Interest: Examining the Evidence on Racial Dynamics in Colleges and Universities, ed. Mitchell Chang, Daria Witt, James Jones, and Kenji Hakuta, 126-70. Stanford, CA: Stanford University Press.

Mitchell, Sara McLaughlin, and Vicki L. Hesli. 2013. "Women Don't Ask? Women Don't Say No? Bargaining and Service in the Political Science Profession." PS: Political Science \& Politics 46 (2): 355-69.

Monforti, Jessica Lavariega, and Melissa Michelson. 2008. "Diagnosing the Leaky Pipeline: Continuing Barriers to the Retention of Latinas and Latinos in Political Science." PS Political Science \& Politics 41 (1): 161-66.
American Political Science Association Task Force on Advancement of Women in Academic Political Science in the United States. 2004. Women's Advancement in Political Science. Washington, DC: American Political Science Association.

Brettscheider, Marla. 2011. "Heterosexual Political Science." PS: Political Science $\mathcal{E}$ Politics 44 (1): 23-26.

Breuning, Marijke, and Kathryn Sanders. 2007. "Gender and Journal Authorship in Eight Prestigious Political Science Journals."

PS: Political Science \& Politics 40 (2): 347-51.

Butcher, Charity, and Timothy Kersey. 2015. "When Winning Is Really Losing: Teaching Awards and Women Political Science Faculty." PS: Political Science \& Politics 48 (1): 138-41.

Evans, Heather, and Ashley Moulder. 2011. "Reflecting on a Decade of Women's Publications in Four Top Political Science Journals.” PS: Political Science \& Politics 44 (4): 793-98.

Fraga, Luis Ricardo, Terri E. Givens, and Dianne M. Pinderhughes. 2011. "Political Science in the 21st Century." APSA Task Force Report, October. Available at www. apsanet.org/21stcentury.

Ginther, Donna. 2004. "Gender Differences in Salary and Promotion in Political Science." Paper presented at the APSA Workshop on Women's Advancement in Political Science, Washington, DC, March 5 .

Greenberg, Jon. 2015. "7 Reasons Why Colorblindness Contributes to Racism Instead of Solves It.” Everyday Feminism. Available at http://everydayfeminism. com/2015/02/colorblindness-adds-to-racism.

Henehan, Marie T., and Meredith Reid Sarkees. 2009. "Open Doors and Closed Ceilings: Gender-Based Patterns and Attitudes in the International Studies Association." International Studies Perspectives 10 (4): 428-46.

Hero, Rodney. 2015. "Reflections on How Political Science Can Be More Diverse." PS: Political Science \& Politics 48 (3): 469-71.

Hesli, Vicki. 2013. "Mobilizing Resources for Change: Who Experiences Discrimination and Why?" Paper presented at the Annual Meeting of the Southern Political Science Association, Orlando, FL, January.

Hesli, Vicki L., and Jae Mook Lee. 2013. "Job Satisfaction in Academia: Why Are Some Faculty Members Happier Than Others?” PS: Political Science \& Politics 46 (2): 339-54

June, Audrey Williams. 2015. "The Invisible Labor of Minority Professors." The Chronicle of Higher Education. Available at www.chronicle.com/article/ The-Invisible-Labor-of/234098

Lilienfeld, Eva. 2016. "How Student Evaluations Are Skewed against Women and Minority Professors.” The Century Foundation. Available at https://tcf.org/ content/commentary/student-evaluations-skewed-women-minority-professors.
Monroe, Kristen Renwick, Jenny Choi, Emily Howell, Chloe Lampros-Monroe, Crystal Trejo, and Valentina Perez. 2014. "Gender Equality in the Ivory Tower, and How Best to Achieve It." PS: Political Science \& Politics 47 (2): 418-26.

Mucciaroni, Gary. 2011. "The Study of LGBT Politics and Its Contributions to Political Science." PS: Political Science \& Politics 44 (1): 17-21.

Novkov, Julie, and Scott Barclay. 2010. "Lesbians, Gays, Bisexuals, and the Transgendered in Political Science: Report on a Discipline-Wide Survey." PS: Political Science \& Politics 43 (1): 95-106.

Padilla, Amado. 1994. "Ethnic Minority Scholars, Research, and Mentoring." Educational Researcher 23 (4): 24-7.

Pyke, Karen. 2011. "Service and Gender Inequity among Faculty." PS: Political Science \& Politics 44 (1): 85-87.

Sinclair-Chapman, Valeria. 2015. "Leveraging Diversity in Political Science for Institutional and Disciplinary Change." PS: Political Science \& Politics 48 (3): $454-58$.

Smith, Daryl. 200o. "How to Diversify the Faculty." Academe. Available at https:// diversity.illinois.edu/SupportingDocs/DRIVE/How\%2oto\%2oDiversify\%2O the\%2oFaculty.pdf.

Teele, Dawn, and Kathleen Thelen. 2017. "Gender in the Journals: Publication Patterns in Political Science.” PS: Political Science \& Politics 50 (2): 433-47.

Thomas, Peter L. 2017. "White Men of Academia Have an Objectivity Problem." Huffington Post. Available at www.huffingtonpost.com/ entry/more-on-white-men-of-academia-student-and-self-evaluation us 593 a 8204 e 4 bob65670e 56963.

Toven, Michelle. 2015. "New Research Examines Lack of Diversity in Poli Sci and What Needs to Change." Gender Focus. Available at www. gender-focus.com/2015/08/29/diversity-political-science/\#sthash. 5YBlTkFb.dpuf.

US Department of Education, National Center for Education Statistics. 2017. The Condition of Education 2017 (NCES 2017-144), Characteristics of Postsecondary Faculty. Available at https://nces.ed.gov/fastfacts/display. asp?id=61.

Uttl, Bob, Carmela A. White, and Daniela Wong Gonzalez. 2017. "Meta-Analysis of Faculty's Teaching Effectiveness: Student Evaluation of Teaching Ratings and Student Learning Are Not Related." Studies in Educational Evaluation 54 (September): 22-42.

Whitaker, Manya. 2017. "The Unseen Labor of Mentoring." Chronicle Vitae. Available at https://chroniclevitae.com/news/1825-the-unseen-labor-ofmentoring. 


\section{Navigating Polftical Science}

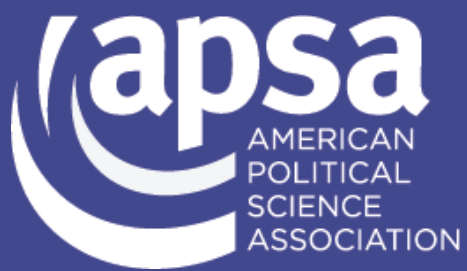

Navigating the political science discipline can be a daunting task for those unfamiliar with its nuances. APSA's newest resource offers advice on both handling the challenges presented by the discipline and taking full advantage of its opportunities.

Navigating Political Science:ProfessionalAdvancement $\mathcal{E}$ Success in the Discipline, edited by Kent Worcester, brings together some of the most noteworthy, discipline-focused contributions to APSA journals published over the past couple of decades. With 28 chapters by 45 contributors, the book touches on topics that range from peer review, mentoring, and faculty governance, to blogging, data collection, and digital media in the classroom. The book should prove relevant for political scientists across the board, from aspiring ABDs to seasoned PhDs.

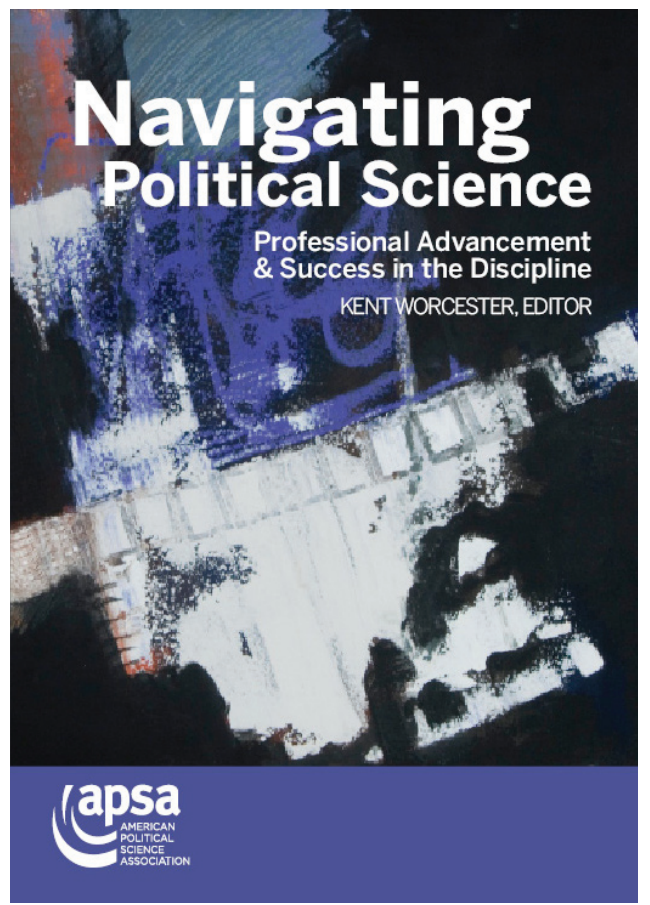

\section{Read the free PDF available online or purchase in paperback!}

\section{Scan to learn more or visit www.apsanet.org/navigating}

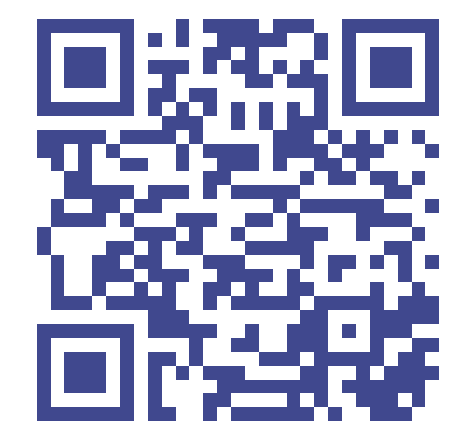

